\title{
Excision of Instructional Leadership at Colleges of Teacher Education
}

\author{
Atalay Mesfin (MA) \\ Debre Marks college of Teacher Education, Debre Markos, Ethiopia \\ Molalign Tamru (PhD) \\ Debre Markos University, Debre Markos, Ethiopia
}

\begin{abstract}
This investigation was predominantly focused on surveying the execution of instructional leadership capacities execution at universities of educator training in the Amhara district. To this end, the examination attempted to answer the degree of instructional leadership work execution; In responding to the above exploration question, the investigates has utilized a simultaneous blended exploration plan. The information gathered through various instruments from 196 instructors and 351 third year customary understudies were broke down by considering the idea of information gathered. Subjective information investigation methods (portrayal, understanding, and direct citation) were utilized to break down the information gathered through the meeting, record audit and center gathering conversation; though, the quantitative information examination procedures (recurrence, mean, and percent) were utilized to dissect the information gathered through shut finished things of the surveys. From the examinations of the information gathered, the significant discoveries were champion in the investigation. In light of the mean percent, the executions of instructional authority capacities were $46.75 \%$. At long last, the researcher has reached significant inference under each exploration question. In light of this, suggestions were sent to various partners like MoE, REB, college senior members, instructors, and understudies.
\end{abstract}

Keywords: Instructional leadership, practice and leadership

DOI: $10.7176 /$ RHSS/11-5-03

Publication date:March $31^{\text {st }} 2021$

\subsection{Background of the Study}

As instruction is critical to sustaining residents, the training associations are additionally significant. Colleges of educator instruction are a spot where accomplished labor is relied upon to rise. Any human improvement agrees that it is the HR of a country and not its capital or normal assets that at last decide the pace of its financial and social turn of events (portage, 2000). In any case, accomplished and profoundly prepared work power couldn't be supported without appropriate instructional initiative in training associations. Viable instructional pioneers were seen as culture manufacturers in a given association and they tried to make a scholarly press that cultivated elevated requirements and norms for understudies and just as for instructors (Hallinger and Murphy, 1985). What's more, viable instructional pioneers can get individuals, center around the improvement of understudies' accomplishment, make and convey clear vision, crucial, and plan towards the training change.

Ethiopian Ministry of Education gives due consideration for the authority preparing of rudimentary and auxiliary college pioneers in the nation. This is because MoE, (2007) rule gives accentuation for the professionalization of instructional authority by planning and executing obvious and spurring vocation improvement structure in the training framework for pioneers (MoE,2007). Then again, Postgraduate Diploma in College Leadership Program (PGDSL) was propelled in 2013 for essential and optional college pioneers; a Master's Degree in college leadership for auxiliary college initiative program was likewise begun in 2014 and postgraduate authentication in essential and optional college oversight program was begun in 2015 . All the projects, PGDSL, a post-graduate in-college initiative, and different projects give due consideration for the instructional leadership of essential and auxiliary college pioneers.

MoE, (2002) expressed that training is exceptionally expected to assume an essential job in the general exercises of the nation for its general turn of events. To put this significance into impact, allocating powerful instructional pioneers according to the standard is significant. To do these principles, every one of those befuddling circumstances and deviation from the logical instructional initiative capacity execution pushed the scientist to assess the instructional leadership work execution, deterrent elements, and openings at colleges of instructor training from the point of view of Hallinger and Murphy (1985) instructional authority capacities.

\subsection{Statements of the Problem}

The instructional initiative practices mean to build up the instructional procedure rises positive and valuable relations with understudies and educators build up the expert aptitudes and assume a significant liability on the accomplishment of the objectives of an establishment by empowering hierarchical culture (Scott and Weber, 2008). Here the fact of the matter is changing authoritative societies which are significant and consider as an 
essential issue in changing any instructive association fundamentally the showing learning process. In this manner, instructional authority is in a different spot from different structures as it has a key job in the powerful educating and learning forms along with the changing social structure and thought in a given association (Ersozlu and Saklan, 2016). Presently a day, colleges of encouraging training are experiencing various issues that came about the inappropriate instructional initiative. The issue of instructional authority is over explored. However, practically a large number of the explores were led on essential and auxiliary training instructional authority Practices and difficulties (Atkinson, 2013; Tadesse, 2014; Hicks, 2014; and Deggay,2015). An examination led to tertiary instruction is extremely constrained. The normal issues investigated by various analysts and researchers are talked about as follows to demonstrate holes to be filled by this examination try. Despite the fact that the ideas of instructional leadership are well known and has its model recommended by researchers, writing on the instructional initiative of tertiary training are constrained. Many are centered around optional training and didn't thoroughly concentrated on the execution, block components, and chances of instructional authority work execution at universities of instructor training. For example, an investigation on key instructional initiative execution of college directors (Ghavifekr and et al, 2014) was limited by instructors' discernments and profoundly centered around instructional leadership saw by teachers. In addition, privately led research by Maeregu and et al (2016) on difficulties of instructive leadership improvement program was worried about surveying the current instructive authority advancement projects to distinguish the significant difficulties upset to execute Hallinger and Murphy (1985) instructional initiative capacity. Moreover, the examination wasn't explicitly centered around instructional initiative capacity execution.

In addition, Syarwan and Maznah (2012) led an examination that focused on instructional leadership on overseeing instructional time which left the other nine instructional initiative capacities like giving motivations to educators, giving motivators to learning, proficient turn of events, characterizing strategic vision and advancing positive learning condition. Then again, Davis (1983) additionally led irregular examination which centers around authority in advanced education. His exploration gave due accentuation for examining initiative aptitudes and styles. He didn't see the instructional leadership work with explicit measurements.

For the most part, undoubtedly, huge numbers of the past analysts didn't utilize the Hallinger and Murphy (1985) instructional authority work if there should be an occurrence of instructor training universities. Some of them led an investigation by utilizing Hallinger and Murphy's (1985) instructional authority work in rudimentary and auxiliary colleges. The researcher didn't find an examination which is directed on instructional leadership work execution, impediment components, and openings at universities of educator training. Hence, the researcher represented the accompanying fundamental examination question to be replied by the exploration is the extent of instructional leadership functions executed in the leadership practice at colleges of teacher education?

1.3 Objective of the Study: This article aimed to answer the extent of instructional leadership execution in colleges of teacher education.

\section{Research Design}

For the flow research, the researcher considered for both quantitative and subjective information to respond to the examination question presented in section one. Along these lines, the focal reason of this examination is that the utilization of quantitative and subjective information can gives a superior comprehension of the exploration issue than utilizing just a single alone. In particular, in this examination, the researcher distinguished the execution of instructional leadership from Hallinger and Murphy (1985) capacities; in this manner, the quantitative part was utilized to gather and break down information about autonomous variable, degree of instructional authority work execution while the subjective part was utilized to gather and investigate the open doors accommodated the execution of instructional initiative and difficulties.

\subsection{Sample size of the study}

There is no obvious response for the right example size as it relies upon the reason for the examination and the idea of the populace under investigation (Louis, 2007) he likewise included that the bigger example size gives more prominent dependability of the investigation. Besides, contingent upon the sort of investigation to be played out, the scientist requires bigger examples. As per the sort of devices utilize to gather information the example size of the members can be changed (Kothari, 2004). Then again, for distinct explores, it is entirely expected to test $10-20 \%$ of the populace. Even though this range will change with the size of the populace contemplated. As a general rule, a suitable example size relies upon various variables. Because of those realities, the researcher needs to choose tests from educators and understudies by utilizing corresponding separated irregular inspecting procedure, the examples of the examination were chosen by utilizing Gay, L. furthermore, Airasian, P table of test join which was created by the United States workplaces of instruction. As expressed at the table of test joins together, if the all-out populace is somewhere in the range of 3500 and 4000 the example 
joins ought to be 346 or 351 (Gay, L. what's more, Airasian, P. 2000). In light of this, the complete populaces for this investigation were 400 educators and 3762 understudies. All senior members, bad habit dignitaries, and division heads are considered as a major aspect of instructors. Along these lines, the researcher chooses 351 understudies' and 196 instructors (the quantities of understudies were 3762 while the number of educators was 400 .

Table 2.1 summery of Total Population and Sample Unit

\begin{tabular}{|c|c|c|c|c|c|c|c|c|c|c|c|c|c|}
\hline \multirow[t]{3}{*}{ No } & \multirow[t]{3}{*}{ College } & \multicolumn{6}{|c|}{ Teacher } & \multicolumn{6}{|c|}{ Students } \\
\hline & & \multicolumn{3}{|c|}{ Total population } & \multicolumn{3}{|c|}{ Sample unites } & \multicolumn{3}{|c|}{ Total population } & \multicolumn{3}{|c|}{ Sample unites } \\
\hline & & $\mathrm{M}$ & $\mathrm{F}$ & $\mathrm{T}$ & $\mathrm{M}$ & $\mathrm{F}$ & $\mathrm{T}$ & $\mathrm{M}$ & $\mathrm{F}$ & $\mathrm{T}$ & $\mathrm{M}$ & $\mathrm{F}$ & $\mathrm{T}$ \\
\hline 1 & DebreMarkos & 91 & 13 & 104 & 42 & 8 & 50 & 607 & 336 & 943 & 57 & 31 & 88 \\
\hline 2 & DebreBirhan & 89 & 18 & 107 & 41 & 11 & 52 & 378 & 408 & 786 & 35 & 38 & 73 \\
\hline 3 & Woldiya & 89 & 13 & 102 & 42 & 9 & 51 & 389 & 264 & 653 & 36 & 25 & 61 \\
\hline 4 & Enjibara & 76 & 11 & 87 & 37 & 6 & 43 & 590 & 790 & 1380 & 55 & 74 & 129 \\
\hline \multicolumn{2}{|c|}{ Total } & 345 & 55 & 400 & 162 & 34 & 196 & 1964 & 1798 & 3762 & 183 & 168 & 351 \\
\hline
\end{tabular}

\subsection{Data Gathering Instruments}

\subsubsection{Questionnaire}

A questionnaire is a paper and pencil instrument that poses similar inquiries of all individuals from the example join together, and which respondents can reply at their comfort (Gall and Borg, 2007). In light of the above portrayal, the scientist picked survey since it is a snappy method of get-together information and it can arrive at countless subjects and it is broadly utilized in most instructive explores (Koul, 1984). The surveys were intended for instructors, dignitaries, and understudies. Both the polls were structured in English and were incorporated both open-finished and shut finished inquiries. The shut finished examiner was adjusted from Hallinger PIMRS by requesting that authorization from him utilize the examiner (The polls is a Lickert scale type having an option going quite often, now and again, now and then, sometimes and never). The analyst got an authorization letter from Hallinger to adjust and utilize the examiner to gather information. Different instruments used to gather information about prevention factors that influence the execution of instructional authority capacities and openings gave to execute instructional initiative capacity was self-created polls. Those surveys were created dependent on the writing audit and examination questions. By and large, to gather information 50 close finished thing polls were adjusted from Hallinger PIMRS and it was interpreted of into Amharic by welcoming language educator to make it justifiable to understudy members. The other 15 close finished things were additionally evolved by the scientist himself to gather information about block variables of instructional initiative capacity execution.

\subsubsection{Document Review (DR)}

The document review was led in each of the four colleges of instructor training by utilizing archive audit agendas. Diverse understudy's motivation reports, instructor reports about their understudies and office minutes, college reports, territorial training Bureau criticism reports, cosmetics class reports, and the college vital arrangement were checked and dissected well so as to reach a legitimate and solid resolution. At long last, the scholastic commission minutes were looked into and crosschecked with other information got through various information assortment apparatuses. In particular, the archived survey was imperative to perceive how much the college of instructor training remember crucial vision for their yearly arrangement and vital arrangement, regardless of whether they plan their vision and mission dependent on logical methodology or not and discuss adequately with educators. The report survey was imperative to locate the information acquired from members through a poll. Archive audit agendas with twelve things were readied.

\subsubsection{Focus Group Discussion (FGD)}

The focus group discussion was driven in every one of the four colleges of teacher preparation by using chronicle review plans. Assorted understudy's inspiration reports, educator reports about their understudies and office minutes, college reports, regional preparing Bureau analysis reports, beauty care products class reports, and the college essential game plan was checked and analyzed well to arrive at a real and strong goal. Finally, the educational commission minutes were investigated and crosschecked with other data that got past different data combination devices. Specifically, the filed review was basic to see how much the college of teacher preparing recollect critical vision for their yearly course of action and crucial plan, whether or not they plan their vision and mission subject to legitimate philosophy or not and examine satisfactorily with instructors. The report review was basic to find the data obtained from individuals through a survey. File review plans with twelve things were prepared

\subsubsection{Interview}

A meeting is a lot of verbal inquiries posed by the researcher and verbal reactions are given by the interviewee (Gall and Borg, 2007). For this investigation, semi-organized inquiries questions were set up to accumulate 
direct data from the members. The explanation behind utilizing a semi-organized meeting is because of its bit of leeway of adaptability where new inquiries were sent during the meeting dependent on the reactions of the interviewee. Thus, four inquiries questions were planned for witnesses to evoke thoughts.

Both the underlying and the recently included inquiries questions were talked about with the sources in the Amharic language to lessen correspondence boundaries and to get point by point data. The reason for the meeting was to get substantial confirmations from both verbal and nonverbal confirmations that may not be conceivable by the poll. The interviewee was four college senior members and they were met once during scholastic commission meeting orchestrated by the territorial instruction Bureau in January 2018. This was a significant instrument to respond to the exploration question about prevention components and openings gave to execute instructional authority capacities.

\subsection{Data Analysis Techniques}

\subsubsection{Quantitative Data Analysis Technique}

A quantitative information investigation procedure was utilized to dissect information gathered through a poll. After the crude information gathered, it was assembled, sorted out, and dissected with quantitative information investigations methods. From the quantitative information investigation strategy Percentage, recurrence, Mean, standard deviation was utilized. A portion of the subtleties of quantitative information assortment instruments is introduced under here.

3 DATA ANALYSIS AND INTERPRETATION OF RESULTS

3.1 The Extent of Instructional Leadership function execution based on Hallinger and Murphy (1985) Instructional Leadership Function (Research Question One).

Table 3.1: Teachers response on the extent of instructional leadership function execution

\begin{tabular}{|c|c|c|c|c|c|c|c|c|}
\hline \multirow[t]{2}{*}{ Key function } & \multirow{2}{*}{$\circlearrowright \equiv$} & \multicolumn{5}{|c|}{ Level of agreement } & \multirow[b]{2}{*}{ Total } & \multirow[b]{2}{*}{ Missing } \\
\hline & & 5 & 4 & 3 & 2 & 1 & & \\
\hline \multirow[t]{2}{*}{ Framing the college goals( 5 items $)$} & $F$ & 3.6 & 5.6 & 45.2 & 85.4 & 54.2 & 194 & 2 \\
\hline & $\%$ & 1.83 & 2.86 & 23.06 & 43.56 & 27.65 & 98.8 & 1.2 \\
\hline \multirow[t]{2}{*}{ Communicating college goals (5 items) } & $F$ & 3.8 & 7.2 & 52.2 & 80.8 & 46 & 190 & 6 \\
\hline & $\%$ & 1.93 & 3.66 & 26.62 & 41.2 & 23.5 & 96.8 & 3.2 \\
\hline \multirow{2}{*}{$\begin{array}{l}\text { Supervision and evaluating instructions(5 } \\
\text { items) }\end{array}$} & $F$ & 1.8 & 7.6 & 60 & 74.4 & 52.2 & 196 & -- \\
\hline & $\%$ & .91 & 3.89 & 30.61 & 37.96 & 26.63 & 100 & - \\
\hline \multirow[t]{2}{*}{ Coordinating the curriculum( 5 items $)$} & $F$ & 2.8 & 10.6 & 50 & 90.8 & 41.8 & 196 & - \\
\hline & $\%$ & 1.43 & 5.41 & 25.51 & 46.33 & 21.32 & 100 & - \\
\hline \multirow[t]{2}{*}{ Monitoring students' progress(5 items) } & $F$ & 2.4 & 6 & 67.6 & 67 & 53 & 196 & - \\
\hline & $\%$ & 1.22 & 3.06 & 34.49 & 34.18 & 27.04 & 100 & - \\
\hline \multirow{2}{*}{ Protecting instructional time(5 items) } & $F$ & 00 & 5.6 & 69.2 & 72 & 49.2 & 196 & - \\
\hline & $\%$ & 00 & 2.86 & 35.31 & 36.73 & 25.1 & 100 & - \\
\hline \multirow{2}{*}{$\begin{array}{l}\text { Promoting professional development(5 } \\
\text { items) }\end{array}$} & $F$ & 4.6 & 12.4 & 60.6 & 80.4 & 38 & 196 & - \\
\hline & $\%$ & 2.35 & 6.33 & 30.92 & 41.02 & 19.38 & 100 & - \\
\hline \multirow[t]{2}{*}{ Maintaining high visibility(5 items) } & $F$ & 3.4 & 4.6 & 51 & 83.2 & 53.8 & 196 & - \\
\hline & $\%$ & 1.73 & 2.35 & 26.02 & 42.45 & 27.45 & 100 & - \\
\hline \multirow{2}{*}{$\begin{array}{l}\text { Providing incentives for teachers }(5 \\
\text { items) }\end{array}$} & $F$ & 5 & 13.6 & 56.2 & 70.4 & 50.8 & 196 & - \\
\hline & $\%$ & 2.55 & 6.94 & 28.67 & 35.92 & 25.92 & 100 & - \\
\hline \multirow{2}{*}{$\begin{array}{l}\text { Providing incentives for learning }(5 \\
\text { items) }\end{array}$} & $F$ & 00 & 4.2 & 63.8 & 80.2 & 47.8 & 196 & - \\
\hline & $\%$ & 00 & 2.14 & 32.55 & 40.92 & 24.39 & 100 & - \\
\hline
\end{tabular}

Key: [5] Represents Almost Always, [4] Represents frequently, [3] Represents sometimes [2] Represent Seldom [1] Represents Almost Never

Based on table 4.1 above, teacher participants responded differently in different instructional leadership function. They responded as almost always and frequently were $(1.83 \%, 5.72 \%, 4.28 \%, 9.99 \%, 2.64 \%, 6.24 \%$, $3.98 \%$, $12.35 \%$, $1.22 \%$ and
5.2
$\%$
and those who responded as seldom and almost never was $(77.74, \% 54.69 \%, 77.93 \%, 48.6 \%, 78.98 \%, 46.01 \%, 88.78 \%$ ,48.77\%, $76.84 \%$ and $50.31 \%$ ); whereas, $(23.06 \%, 26.62 \%, 30.61 \%, 25.51 \%, 34.49 \%, 35.31 \%, 30.92 \%, 26.02 \%$, $35.92 \%$ and $40.92 \%$ ) responded as instructional leadership executed sometimes. Based on the above teachers' response on the execution of instructional leadership function, we conclude that the extent of execution of instructional leadership function was found almost never and seldom in four colleges of teacher education. 
Table 3.2: Students Response on the Extent of Instructional Leadership Function Execution

\begin{tabular}{|c|c|c|c|c|c|c|c|c|}
\hline \multirow[t]{2}{*}{ Key function } & \multirow[b]{2}{*}{$\vec{\Xi}$} & \multicolumn{5}{|c|}{ Level of agreement } & \multirow[b]{2}{*}{ Total } & \multirow[b]{2}{*}{ Missing } \\
\hline & & 5 & 4 & 3 & 2 & 1 & & \\
\hline \multirow[t]{2}{*}{ Framing the college goals (5 items) } & $F$ & 22.8 & 50.2 & 67.8 & 121.8 & 85.4 & 347 & 3 \\
\hline & $\%$ & 6.5 & 14.3 & 19.3 & 34.6 & 24.3 & 99 & 1 \\
\hline \multirow[t]{2}{*}{ Communicating college goals (5 items) } & $F$ & 29.2 & 32.2 & 78.2 & 129.2 & 82.2 & 351 & -- \\
\hline & $\%$ & 8.32 & 9.17 & 22.28 & 36.81 & 23.42 & 100 & \\
\hline \multirow{2}{*}{$\begin{array}{l}\text { Supervision and evaluating instructions( } 5 \\
\text { items) }\end{array}$} & $F$ & 28.4 & 44.2 & 87.4 & 103.8 & 87.2 & 351 & -- \\
\hline & $\%$ & 8.09 & 12.59 & 24.90 & 29.57 & 24.84 & 100 & \\
\hline \multirow[t]{2}{*}{ Coordinating the curriculum(5 items) } & $F$ & 30 & 38 & 75 & 128 & 80 & 351 & --- \\
\hline & $\%$ & 8.6 & 10.8 & 21.4 & 36.4 & 22.8 & 100 & --- \\
\hline \multirow[t]{2}{*}{ Monitoring students' progress(5 items) } & $F$ & 27.6 & 32.6 & 96 & 103.6 & 90.2 & 350 & 1 \\
\hline & $\%$ & 7.86 & 9.28 & 27.4 & 29.5 & 25.68 & 99.72 & 0.28 \\
\hline \multirow[t]{2}{*}{ Protecting instructional time(5 items) } & $F$ & 33.2 & 34.2 & 84 & 106.8 & 92.8 & 351 & -- \\
\hline & $\%$ & 9.5 & 9.74 & 23.93 & 30.42 & 26.44 & 100 & -- \\
\hline \multirow{2}{*}{$\begin{array}{l}\text { Promoting professional development(5 } \\
\text { items) }\end{array}$} & $F$ & 35.2 & 41.2 & 79.4 & 118.4 & 76.4 & 350.6 & 0.4 \\
\hline & $\%$ & 10.03 & 11.73 & 22.62 & 33.73 & 21.77 & 99.88 & 0.12 \\
\hline \multirow[t]{2}{*}{ Maintaining high visibility(5 items) } & $F$ & 27.8 & 40.8 & 73 & 124.4 & 84 & 350 & 1 \\
\hline & $\%$ & 7.92 & 11.62 & 20.87 & 35.4 & 23.91 & 99.72 & 0.28 \\
\hline \multirow[t]{2}{*}{ Providing incentives for teachers ( 5 items) } & $F$ & 30 & 42.2 & 77 & 110.4 & 89.6 & 349.2 & 1.8 \\
\hline & $\%$ & 8.54 & 12.03 & 21.94 & 31.45 & 25.52 & 99.48 & 0.52 \\
\hline \multirow[t]{2}{*}{ Providing incentives for learning(5 items) } & $F$ & 25.2 & 20.4 & 98.4 & 123.6 & 81.4 & 349 & 2 \\
\hline & $\%$ & 7.18 & 5.81 & 28.03 & 35.21 & 23.19 & 99 & 1 \\
\hline
\end{tabular}

NB. When the researcher said that 0.12 missing mean that $0.12 \times 5 \times 5=3$ individual missed the item, which means, the questionnaire has five item and each items has also five alternatives.

As one can see from table 4.2 above, understudies were gotten some information about the execution of instructional authority in their college dependent on ten instructional initiative capacities. They rate their inclination uniquely, in contrast, to consistently up to never. Most understudies accepted that instructional leadership capacities weren't executed in their college as they reacted never $(24.3 \%, 23.42 \%, 24.84 \%, 22.8 \%$, $25.68 \%, 26.44 \%, 21.77 \%, 23.91 \%, 25.52 \%$, and $23.19 \%$ ) for surrounding the college objectives, conveying college objectives, managing and accessing guidelines, planning the educational program, observing understudies' advancement, securing instructional time, advancing proficient turn of events, keeping up high permeability, giving impetuses to educators and giving motivating forces to adapting individually. While different understudies reacted as quite often and oftentimes about the instructional leadership work execution at their college of instructor training were $(20.8 \%, 17.49 \%, 20.68 \%, 19.4 \%, 17.14 \%, 19.24 \%, 21.76 \%, 19.54 \%$, $20.57 \%$ and $12.99 \%$ ). These reactions were the entirety of quite often and now and again for surrounding the college objectives, conveying college objectives, managing and assessing guidelines, planning the educational program, checking understudies' advancement, ensuring instructional time, advancing proficient turn of events, keeping up high permeability, giving impetuses to instructors and giving motivators to adapting individually. The remainder of member understudies were reacted that instructional authority work was executed rarely. For the most part, from the understudies' reaction, instructional initiative capacities were not executed at colleges of instructor training. The reaction clarified above were aggregate information acquired from four universities of instructor training. The degrees of instructional authority work execution at various universities of educator training were likewise treated independently and the finding showed that execution of motivator for learning (DMCTE $35.45 \%$, DBCTE 44.44\%, ECTE 57.58\% and WCTE 44.59\%). ECTE (57.58\%), elevating proficient improvement was to be discovered $42.18 \%$ at DMCTE, $42.53 \%$ at DBCTE, $63.72 \%$ at ECTE, and $42.56 \%$ at WCTE. All universities of instructor training aside from ECTE were executed beneath normal. The execution of checking understudies' advancement additionally discovered $44.82 \%$ at DMCTE, $44.38 \%$ at DBCTE, $59.32 \%$ at ECTE, and $45.18 \%$ at WCTE. From this, one can reason that there was execution distinction in various college of educator training regardless of whether the total worth was underneath normal that is $48.425 \%(44.82+44.38$ $+59.32+45.18=193.7 / 4)($ see reference section F).

Essentially, the subjective information gathered through open-finished poll guaranteed that instructional leadership capacities were not executed at colleges of educators' training. Accordingly, the accompanying thoughts were raised by some educator respondents from various universities of instructor training. The accompanying inquiries were sent to instructors of the college of educator training to examine their perception of instructional authority work execution. Therefore, the accompanying thought was noted by one of the senior 
member "B" respondents.

"To execute instructional initiative capacities, senior members should think about the Logical importance and the way that they executed; and afterward, dignitaries didn't execute Instructional initiative capacities to make the college successful and manufacture learning Network".

Different respondents "An" additionally reacted as

"At the point when I was at the college, I recall some instructional leadership capacity and now I likewise revive my insight from the nearby finished polls. At that point, I accepted that none of the capacity was executed at my college by those pioneers."

What's more, instructors were likewise gotten some information about the manner in which their pioneers speak with them and their understudies the best practice among those Hallinger and Murphy (1985) instructional authority work. In view of this inquiry, practically all educators from various colleges of instructor training accepted that the execution of motivator for learning has become the significant wellspring of contention and disappointment. Likewise, educators were additionally reacted that the college attempted to speak with understudies through conventional gathering however the majority of the understudies were absent.

As reacted by college educators, nonstop expert improvement exercises, with the exception of the Higher Diploma Program (HDP), were missing from the college; the college objective likewise not discussed adequately with the college representatives to make a shared vision. The instructional program was hindered by various startling projects like practicum exercises, competitor choice from various woredas and different projects. Thus, one of the respondents from the college educator reacted as follows.

"Truly, I have seen a post by instructors, head educators, and administrator case manager which tells about the missed class by various reasons; it was extremely despicable to miss such class inside a month, and this would be a proof for the nonattendance instructional initiative execution by and large and explicitly ensuring instructional projects"

Since instructs were approached to compose the college's strategic vision, they attempted to compose as they comprehended. Coming up next are some from numerous which was composed of educators.

"My college visions is to see educated citizen and its missions is to

Produce trained teachers"

"My college visions is to produce democratic citizen and its missions is to produce qualified and honest teachers"

"My college visions is to give community service and its missions is to see well educated teacher throughout the region"

Different educators additionally reacted similarly. The strategic vision of the universities which was composed of them wasn't coordinate with the genuine vision and crucial the college. This showed the strategic vision of the college wasn't discussed successfully with the workers. When confining college vision and mission anyone ought to follow the accompanying significance and logical methodology of structuring vision and strategic a given association. Vision is a proclamation that bargains about the association guide; showing both what the association needs to become and controlling groundbreaking activities by setting a characterized heading for the authoritative development in which it is limited with time (Davis, 2006). In any case, the way that colleges of educator training structure their vision was repudiated with this in light of the fact that the vision and mission didn't disclose to them when where the association is going? Then again, the mission ought to show why the association exists plainly and the unmistakable varied methodologies ought to demonstrate. At the point when we see the above crucial, needs to show the away from presence.

A statement of purpose is an explanation which is utilized as a method of conveying the motivation behind the association. Albeit more often than not it will continue as before for an extensive stretch of time, it isn't exceptional for associations to refresh their statement of purpose and for the most part happens when an association advances. At the point when we see the college vision and mission dependent on the above definition, vision, and strategic the universities revealed to us that universities of educator training aren't confining and conveying their vision and mission adequately. Archive survey was directed dependent on confining and conveying the vision and strategic, instructional time, motivation for educators and learning, management and assessing guidelines, organizing the educational program, checking understudies' advancement, advancing proficient turn of events, and keeping up high permeability. Minutes, letters, and the college plans were investigated. In view of the record survey, the instructional authority work execution wasn't planned, imparted, and executed successfully at all colleges of educator training aside from one. The college dignitaries attempted to make management for educators however observing understudies' advancement, securing instructional time, motivation for learning, and instructors weren't planed in the exercises of educator training universities. The motivation for learning is to some degree attempted to execute at graduation service dependent on understudy's accomplishment once in long term. Consistent expert improvement exercises were not additionally arranged and 
keep up high permeability likewise was not considered as an errand performed by college pioneers. The audit on college yearly and vital arrangement, scholarly commission minutes, college reports, and input from the provincial training agency demonstrated that the execution of instructional initiative capacity was found in risky conditions. For the most part, from the record examination coming up next were significant discoveries, for example, instructional leadership work execution was not examined at office level; the instructional initiative was nor included at HDP preparing at the college; missed class were not follow up by office heads and the report was not there; divisions have not recorded about motivating force for learning and for educators; the office didn't design by incorporating the college crucial vision; offices have archives about the impetus for instructors; office heads didn't speak with educators about ensuring instructional time; scholarly commission of the college didn't take worry about instructional authority execution and senior members have no close to home record to catch up understudies by and large advancement and make management to help offices.

\section{Summary, Conclusion and Recommendations \\ 4.1 Summary}

The respondents of this investigation were 351 haphazardly picked third-year standard understudies and 196 college educators. To do this investigation, Hallinger and Murphy's (1985) instructional leadership capacities were utilized as the applied casing work for this examination. The examination strategy utilized in the investigation was a blended (simultaneous) research plan. Members were chosen by multistage examining followed by exhaustive and separated relative arbitrary inspecting strategy. The information assortment instruments utilized were survey, center gathering conversation, meeting, and archive audit. The information was examined dependent on the idea of information gathered and the scientist attempted to sum up as follows.

\section{Extent of Instructional Leadership Function Execution}

To find out the degree of instructional leadership work execution, the scientist gathers information thoroughly with shut finished surveys from understudies and educator. Educators were reacted diversely in various instructional leadership work execution. Yet, as all respondent instructor reacted that the instructional authority execution is discovered to be $5.348 \%$ (quite often + now and again) while as the other $64.861 \%$ accepted that instructional initiative capacity executed a few times and sometimes and the remainder of $29.794 \%$ accepted that instructional leadership work is never executed at colleges of educator training. The understudy's reaction additionally underpins the instructors' reaction as they reacted $18.874 \%$ quite often and habitually, $32.642 \%$ a few times and $67.358 \%$ sometimes and never which is utilized to fortify the helpless execution of instructional initiative capacities at universities of instructor training. At the point when we attempted to see the reaction of instructors and understudies independently in various universities of educator training, it was discovered that $42.372 \%$ of instructors DMCTE, $43.699 \%$ of instructors DBCTE, $58.814 \%$ of ECTE instructors and $42.916 \%$ of WCTE understudies $58 \%$ of ECTE understudies, $43.699 \%$ of DBCTE understudies, $42.916 \%$ of WCTE understudies and $42.372 \%$ of DMCTE understudies accepted that instructional leadership capacities were not executed adequately dependent on Hallinger and Murphy (1985) instructional authority capacities.

\subsection{Conclusion}

To find the level of instructional organization work execution, the researcher assembles data completely with shut completed reviews from understudies and teacher. Instructors were responded differently in different instructional organization work execution. However, as all respondent teacher responded that the instructional power execution is found to be $5.348 \%$ (regularly + every so often) while as the other $64.861 \%$ acknowledged that instructional activity limit executed a couple of times and in some cases and the rest of 29.794\% acknowledged that instructional organization work is never executed at colleges of instructor preparing. The understudy's response also supports the teachers' response as they responded 18. $874 \%$ regularly and constantly, $32.642 \%$ a couple of times and $67.358 \%$ here and there and never which is used to sustain the defenseless execution of instructional activity limits at colleges of teacher preparing. Right when we endeavored to see the response of teachers and understudies autonomously in different colleges of teacher preparing, it was found that $42.372 \%$ of educators DMCTE, $43.699 \%$ of teachers DBCTE, $58.814 \%$ of ECTE teachers and $42.916 \%$ of WCTE understudies $58 \%$ of ECTE understudies, $43.699 \%$ of DBCTE understudies, $42.916 \%$ of WCTE understudies and $42.372 \%$ of DMCTE understudies acknowledged that instructional organization limits were not executed satisfactorily reliant on Hallinger and Murphy (1985) instructional position limits.

\subsection{Recommendations}

The study was aimed assessing on execution, hindrance factors and provided opportunities for instructional leadership functions at colleges of teacher education from Hallinger and Murphy (1985) functions. Thus, data were collected through different appropriate data collection tools and analyzed by different data analysis techniques and major conclusions were drawn based on the analysis. After these, actions were completed and the researcher forwards the following recommendations for different stakeholders. 


\subsubsection{Recommendation for Ministry of Education}

Based on the findings of the study, the following recommendations were forwarded to ministry of education.

* Ministry of education should work collaboratively with regional education bureau and should develop the guideline to assign college deans which are out of political loyalty and design training mechanisms to enhance college deans' performance on instructional leadership function execution.

* Ministry of education should scale up college leadership program for other higher institutions to nurture good instructional college leaders.

* Employee a supervision strategy to help regional colleges of teacher education.

\subsubsection{Recommendation to Regional Education Bureau}

Regional education bureau should:

* Plan training about instructional leadership function execution to college deans.

* Solve the problems related with lack of resource (by allocating reasonable budget), lack of vision (to allow them to develop their college vision based on their situation) and it also should cooperate with colleges of teacher education to solve the problems timely.

* The statistically significant mean difference was observed among colleges of teacher education. Based on this finding, the regional education bureau should plan experience sharing between colleges of teacher education.

* The ten instructional leadership functions were found in different level of execution. Using this, the regional education bureau should give due emphasis to those loosely executed instructional leadership functions and block up those gaps.

* Communicate with colleges of teacher education and plan instructional leadership function execution together to practice it through CPD.

* Lack of resource was accounted the highest predictive value on the effectiveness of instructional leadership function execution. Then, the regional education bureau should allocate reasonable budget to colleges of teacher education.

\subsubsection{Recommendation for College Deans}

The college deans and should:

* Trained themselves by different mechanisms (from others, reading and asking training from other institutions and experience sharing).

* All the instructional leadership function, framing goals, communicating goals, incentive for learning and incentives for learning, protecting instructional time, coordinating the curriculum and other functions were not executed properly from the perspective of Hallinger and Murphy(1985). Then, the college deans should work exhaustively to execute that instructional leadership function in colaboration with college teachers and students.

* Set clear criteria during execution of incentive for teacher unless it will results demotivation on teachers.

\subsubsection{Recommendation to Teachers and Students}

* College teachers and students should become volunteer to collaborate with deans during the execution of instructional leadership functions like not to be absent at the arranged meetings.

* Teacher should help deans to execute instructional leadership function effectively.

\section{Reference}

C.R.Kuthari, C. (2004). Research Methodology: Methods and Techniques. New Delhi: New Age International Limited Publishers

Creswell, J. W. (2012). Educational Research: Planning, conducting, and evaluating Quantitative and qualitative research. Upper Saddle River: Pearson Education.

Davies, J. (1983) 'Management of higher education in a period.Albany: State University of New York Press.

Deggay,M.(2015). Instructional Leadership Functions of College Principals and Its Effects on Teachers'Performance and Student Achievement. La Consolacion University Philippines.

Ersozlu \& Saklan, (2016). Instructional Leadership in Higher Education: How does It Work?Department of Educational Sciences, Gazi University, Ankara

Gall,T.Gall.P. \& Borg,W.(2007).Educational research. An introduction (8th Ed.) Planning \&Policy, Faculty of Education, University of Malaya

Gay, L., \& Airasian, P. (2000).Educational research: Competencies for analysis and application (6th Edition). Upper Saddle River: Merrill.

Ghavifekr and et al(2014).Factors affecting strategic instructional leadership practice of college

Hallinger, P. \& Murphy, J. (1985). Assessing the instructional management behavior of principals. The Elementary College Journal, 86(2), 217-248.

Maregu B., Firew A., Ashebir B., Gizachew B. \& Alem,A.(2016).Analysis of Educational Management and Leadership Training practice in Ethiopia. Unpublished material. 
MoE. (2007). The teachers development program. Ethiopia: Addis Ababa press

Sockett.S, (2008). Evidence-based leadership development: 4L framework.

Syarwan A. \& Maznah H.(2012). Instructional Leadership Practices of the Excellent College Principals in Aceh, Indonesia.

Tadesse Atnafu.(2014). Instructional leadership practices and challenges in overnment Primaryshools of woreda five in arada sub city.Addis baba.(MAthesis.Unpublished) 